\title{
Claudin-4 differentiates biliary tract cancers from hepatocellular carcinomas
}

\author{
Csaba Lódi ${ }^{1}$, Erzsébet Szabó ${ }^{1}$, Agnes Holczbauer ${ }^{1}$, Enkhjargal Batmunkh ${ }^{1}$, Attila Szíjártó ${ }^{2}$, \\ Péter Kupcsulik², Ilona Kovalszky ${ }^{3}$, Sándor Paku ${ }^{4}$, György Illyés ${ }^{1}$, András Kiss ${ }^{1, *}$ and \\ Zsuzsa Schaff ${ }^{1, *}$ \\ ${ }^{1}$ 2nd Department of Pathology, Semmelweis University, Budapest, Hungary; ${ }^{2} 1$ st Department of Surgery, \\ Semmelweis University, Budapest, Hungary; ${ }^{3}$ First Institute of Pathology and Experimental Cancer Research, \\ Semmelweis University, Budapest, Hungary and ${ }^{4}$ Department of Molecular Pathology, Joint Research \\ Organization of the Hungarian Academy of Sciences and Semmelweis University, Budapest, Hungary
}

\begin{abstract}
The recently identified claudins are dominant components of tight junctions, responsible for cell adhesion, polarity and paracellular permeability. Certain claudins have been shown to have relevance in tumor development, with some of them, especially claudin-4, even suggested as future therapeutic target. The aim of the present study was to analyze the expression of claudin-4 in the biliary tree, biliary tract cancers and hepatocellular carcinomas. A total of 107 cases were studied: 53 biliary tract cancers, 50 hepatocellular carcinomas, 10 normal liver and 10 normal extrahepatic biliary duct samples. Immunohistochemical analysis was performed on conventional specimens and on tissue microarrays as well. Claudin-4 was further investigated by Western blot analysis and real-time RT-PCR. Intense membranous immunolabeling was found for claudin-4 in all biliary tract cancers unrelated to the primary site of origin, namely intrahepatic, extrahepatic or gallbladder cancers. Normal biliary epithelium showed weak positivity for claudin-4. In contrast, normal hepatocytes and tumor cells of hepatocellular carcinomas did not express claudin-4. The results of Western immunoblot analysis and real-time RT-PCR were in correlation with the immunohistochemical findings. Cytokeratins, as CK7 (92\%) and CK19 (83\%) were mostly positive in biliary tract cancers, however, one-third of hepatocellular carcinomas also expressed CK7 (34\%). HSA antibody (HepPar1) reacted with the majority of hepatocellular carcinomas ( $86 \%$ ), while being positive in a low percentage of the biliary tract cancers ( $8 \%)$. In conclusion, this is the first report of a significantly increased claudin-4 expression in biliary tract cancers, which represents a novel feature of tumors of biliary tract origin. Claudin-4 expression seems to be a useful marker in differentiating biliary tract cancers from hepatocellular carcinomas and could well become a potential diagnostic tool.

Modern Pathology (2006) 19, 460-469. doi:10.1038/modpathol.3800549; published online 20 January 2006
\end{abstract}

Keywords: liver; hepatocellular carcinoma; biliary tract cancer; claudin-4; tight junction

Liver and biliary tract cancers, including hepatocellular carcinomas and those arising from intra- or extrahepatic ducts and the gallbladder, are increasing in frequency worldwide. ${ }^{1,2}$ Tumors of mixed histological pattern occur less commonly, and the prognosis of these forms differs from those with homogeneous histological appearance. ${ }^{3,4}$ The differentiation between hepatocellular carcinoma and intrahepatic cholangiocellular carcinoma is not likely to represent a problem in well-differentiated cases, it might, however, prove difficult in moder-

Correspondence: Dr Z Schaff, MD, PhD, DSc, 2nd Department of Pathology, Semmelweis University, Üllői út 93, H-1091 Budapest, Hungary.

E-mail: schaff@korb2.sote.hu

*These authors contributed equally to this study.

Received 26 August 2005; revised and accepted 8 December 2005; published online 20 January 2006 ately or poorly differentiated tumors. Immunohistochemistry for the detection of alpha-fetoprotein, alpha-1-antitrypsin, different types of cytokeratins (CKs), hepatocyte-specific antigen (HSA) and other markers-as syndecan-1, tenascin, mucin 1 and 4 , $\beta$-catenin alteration-might help in establishing the correct diagnosis or to determine the prognosis. ${ }^{5-10}$

Tight junctions, the most apical part of the intercellular junctional complex, play an essential role in maintaining cell polarity and determining paracellular permeability in organs of epithelial origin. ${ }^{11,12}$ Cell adhesion, polarity and intercellular communication are especially important in the trabecular structure of the liver and in the formation of the bile duct system, where tight junctions separate bile flow from plasma. ${ }^{13}$ The members of the recently discovered claudin family are the major components of tight junctions. ${ }^{14} \mathrm{Up}$ to now, 24 types 
of claudins have been detected and their distribution and expression level have been found to vary in different organs and tissues. ${ }^{15,16}$

Certain claudins have been shown to have relevance in carcinogenesis. Claudin-4 was found overexpressed in certain malignancies as in colon and pancreatic carcinomas. ${ }^{17}$ Further, claudin-4 has been suggested as a possible future therapeutic target, described as a receptor for the cytotoxic Clostridium perfringens enterotoxin. ${ }^{18-22} C$. perfringens enterotoxin leads to loss of osmotic equilibrium and cell death by increasing membrane permeability. ${ }^{23}$

Having a common stem cell origin of pancreatic and bile duct system further supports the hypothesis, that biliary tract cancers might also overexpress claudin-4. The question arose whether expression of claudin-4 changes during carcinogenesis or a typical cell-specific expression pattern characterizes the tumors of hepatocellular or bile duct origin. For this reason the present study focused on studying the expression of claudin-4, with the detection of increased expression possibly even leading to the introduction of future therapeutic modalities.

\section{Materials and methods}

Samples from 50 cases of surgically removed hepatocellular carcinomas and 53 cases of biliary tract cancers were obtained with the permission of the Regional Ethical Committee (\#172/2003). The biliary tract cancers arose in the gallbladder $(n=23)$, common bile duct $(n=13)$, hepatic ducts $(n=10)$ and intrahepatic bile ducts (peripheral cholangiocarcinomas) $(n=7)$ (Table 1). In all 10 normal livers and 10 normal, nontumorous extrahepatic biliary tissues removed for other reasons served as controls. The patients received no chemotherapeutic or radiotherapeutic treatment prior to operation. Eight surgically removed biliary tract cancers and eight hepatocellular carcinomas together with four normal livers were immediately transferred to the pathology department (within $10 \mathrm{~min}$ ), where blocks were macrodissected and cut out by an experienced liver pathologist for histopathology, frozen sections, and further molecular biological studies. All cases were photo-documented as well.

\section{Histopathology}

Blocks were fixed in 10\% neutral buffered (in PBS, $\mathrm{pH}$ 7.0) formalin for $24 \mathrm{~h}$ at room temperature, dehydrated in a series of ethanol and xylene and embedded in paraffin. The 3-4 $\mu \mathrm{m}$ thick sections were routinely stained with hematoxylin and eosin and picrosirius red, then PAS reaction with and without diastase digestion, as well as Prussian blue reaction were performed.

\section{Tissue Microarray}

All hematoxylin- and eosin-stained slides were reviewed, a tissue block with the representative tumor was selected from each case, and an area of the tumor on the corresponding slide was encircled. In addition, non-neoplastic liver as well as biliary tissues were also included on the tissue arrays (Figure 1a). Using a tissue arraying instrument (Tissue Micro-Array Builder, Histopathology, Pécs, Hungary), the area of interest in the donor block was cored twice with a $2.0 \mathrm{~mm}$ diameter needle and transferred to a recipient paraffin block (with 24 holes, arranged in four columns and six rows). Tissue microarray blocks were then incubated for $30 \mathrm{~min}$ at $37^{\circ} \mathrm{C}$ to improve adhesion between cores and paraffin of the recipient block. Consecutive $3-4 \mu \mathrm{m}$ thick sections were cut with a microtome. The morphology of tumor and nontumorous tissues on the arrayed samples was identified on hematoxylin- and eosin-stained sections.

\section{Immunohistochemistry}

Whole sections and tissue microarray slides were deparaffinized in xylene and graded ethanol. The deparaffinized sections were treated with the primary antibody against claudin-4 (diluted 1:100, mouse monoclonal, cat\# 32-9400; Zymed Inc., San Francisco, CA, USA) for $60 \mathrm{~min}$ at room temperature

Table 1 Immunohistochemical findings in biliary and hepatocellular carcinomas

\begin{tabular}{|c|c|c|c|c|c|c|}
\hline & Total & Claudin-4 & $C K 7$ & CK 19 & CK 20 & $H S A$ \\
\hline \multicolumn{7}{|l|}{ Bile duct tumor } \\
\hline Gallbladder & 23 & $100 \%(23 / 23)$ & $96 \%(22 / 23)$ & $87 \%(20 / 23)$ & $30 \%(7 / 23)$ & $9 \%(2 / 23)^{a}$ \\
\hline Common bile duct & 13 & $100 \%(13 / 13)$ & $100 \%(13 / 13)$ & $85 \%(11 / 13)$ & $31 \%(4 / 13)$ & $15 \%(2 / 13)^{\mathrm{a}}$ \\
\hline Hepatic ducts & 10 & $100 \%(10 / 10)$ & $90 \%(9 / 10)$ & $80 \%(8 / 10)$ & $30 \%(3 / 10)$ & $0 \%(0 / 10)$ \\
\hline Intrahepatic ducts & 7 & $100 \%(7 / 7)$ & $71 \%(5 / 7)$ & $71 \%(5 / 7)$ & $0 \%(0 / 7)$ & $0 \%(0 / 7)$ \\
\hline Total & 53 & $100 \%(53 / 53)$ & $92 \%(49 / 53)$ & $83 \%(44 / 53)$ & $26 \%(14 / 53)$ & $8 \%(4 / 53)^{\mathrm{a}}$ \\
\hline Hepatocellular carcinoma & 50 & $0 \%(0 / 50)$ & $34 \%(17 / 50)^{\mathrm{a}}$ & $0 \%(0 / 50)$ & $4 \%(2 / 50)$ & $86 \%(43 / 50)$ \\
\hline
\end{tabular}

${ }^{\mathrm{a}}$ Focal positivity. 
a

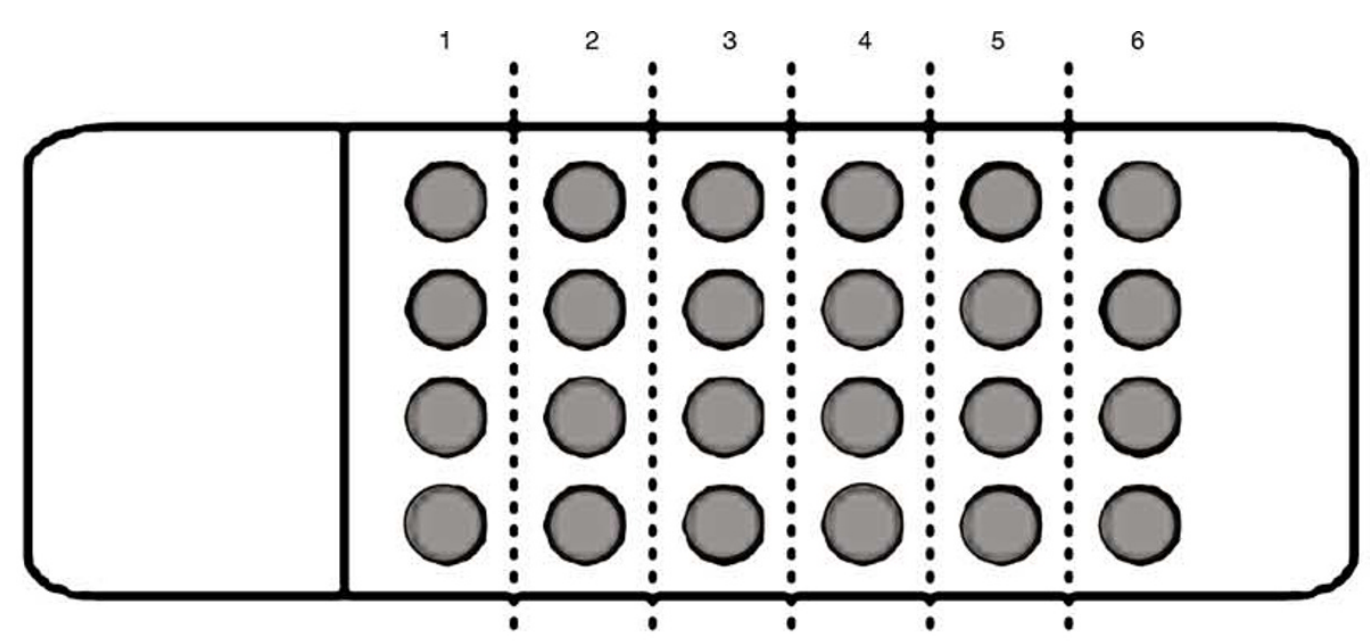

b

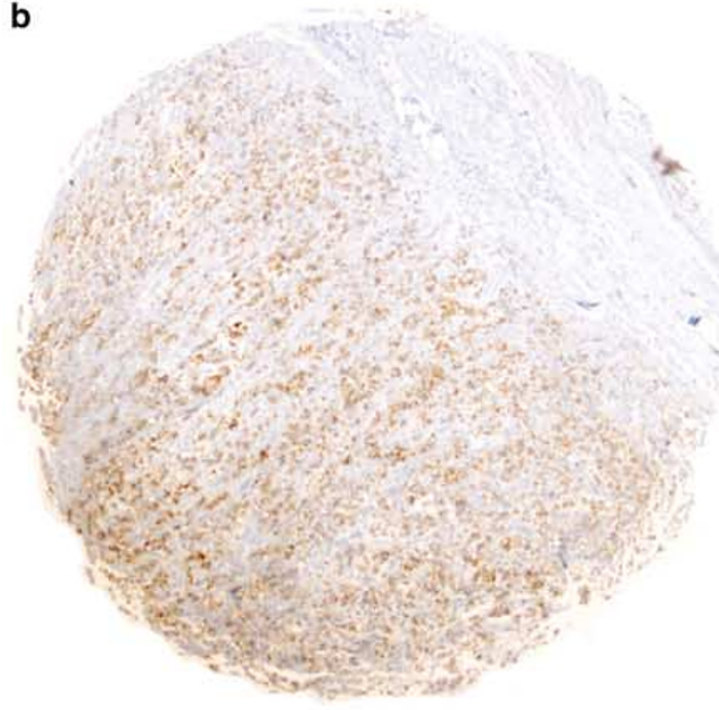

d

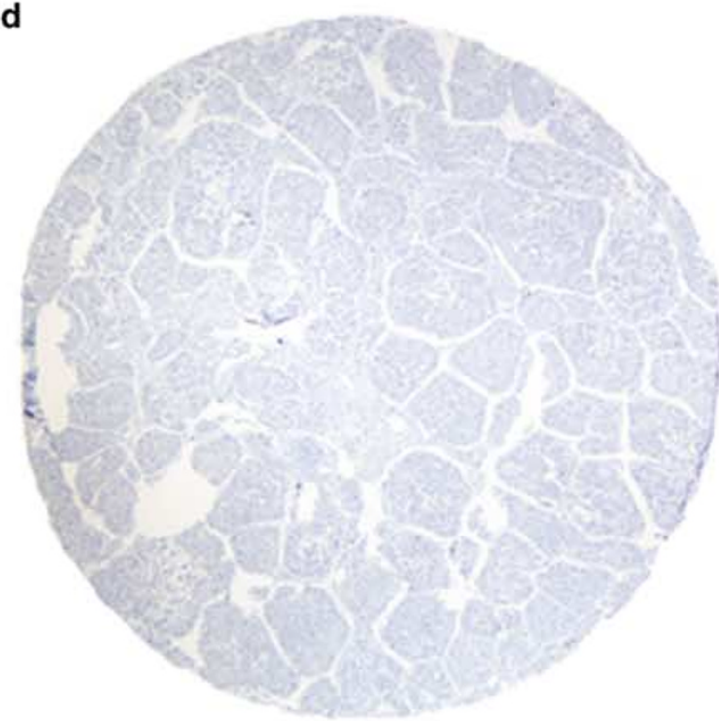

C

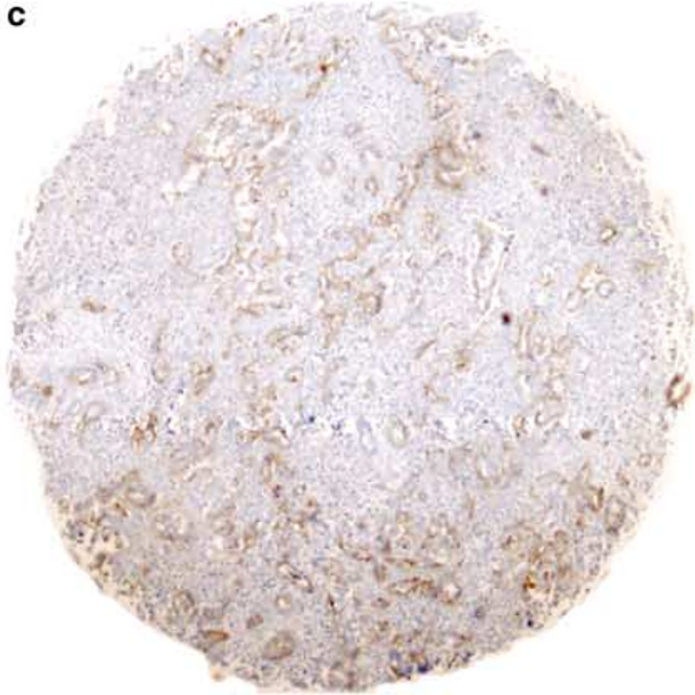

e

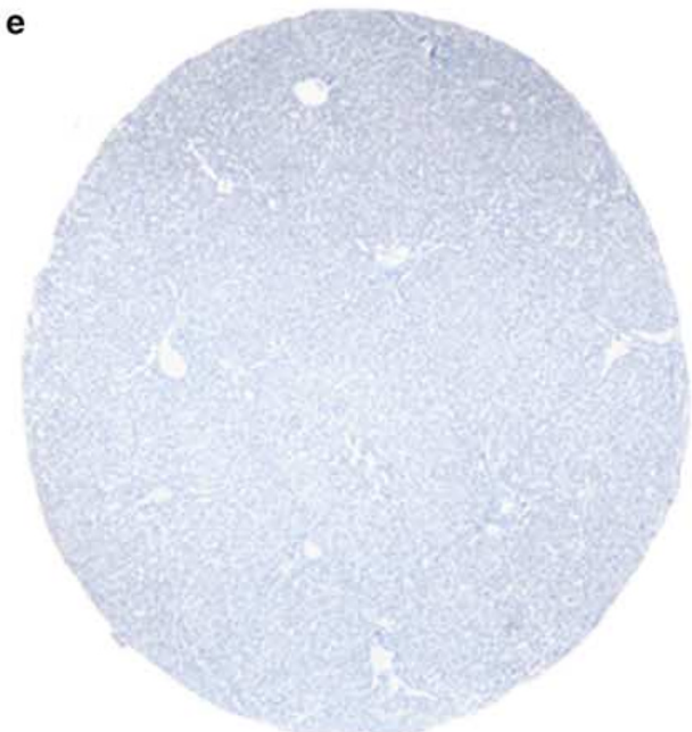

Figure 1 Immunohistochemistry for claudin-4 on tissue microarray. (a) Schematic representation of the samples placed on the tissue microarray according to localization. (1) normal liver, (2) hepatocellular carcinoma, (3) gallbladder tumor, (4) common bile duct tumor, (5) hepatic duct tumor and (6) intrahepatic (peripheral) bile duct tumor. (b) Gallbladder tumor. (c) Common bile duct tumor. (d) Hepatocellular carcinoma. (e) Normal liver. Magnification $\times 28$. 
after treatment with appropriate antigen retrieval (Target Retrieval Solution, DAKO, Glostrup, Denmark, $\mathrm{pH}$ 6; microwave oven for $30 \mathrm{~min}$ ). Primary antibody bound to antigen was detected with a standard streptavidin-biotin-peroxidase technique (Lab Vision Kit, Fremont, CA, USA) and visualized with aminoethyl carbazol or diaminobenzidine as chromogens. Mayer's hematoxylin was used as nuclear counterstain.

Further primary antibodies, anti-CK7 (diluted 1:300, mouse monoclonal, cat\# M7018; DAKO), anti-CK19 (diluted 1:100, mouse monoclonal, cat\# M0888; DAKO), anti-CK20 (diluted 1:600, mouse monoclonal, cat\# M7019; DAKO) and HSA (diluted 1:50, mouse monoclonal, cat\# NCL-HSA; Novocastra Lab., Newcastle-upon-Tyne, UK) were used for $30 \mathrm{~min}$ at $42^{\circ} \mathrm{C}$. These molecular markers were immunostained using an automated immunohistochemical stainer (Ventana ES, Ventana Medical Systems, Tucson, AZ, USA). The matching biotinylated secondary antibody, avidin-streptavidinenzyme conjugate, and chromogenic enzyme substrate ( $8 \mathrm{~min}, 37^{\circ} \mathrm{C}$ each) were used according to the automated protocol. This was followed by application of a copper diaminobenzidine enhancer, hematoxylin counterstaining, and liquid cover slip as part of the automated process. The reagents and secondary antibodies were obtained from Ventana (iView DAB Detection Kit).

Reactions were evaluated independently by four pathologists (ZsS, GyI, AK and CsL), then discussed and presented through a 10-head Olympus BX51 multidiscussion microscope. In all, 10 randomly selected areas of each slide were analyzed using high-power fields objective $(\times 40)$ with 100 cells counted in each field. For evaluation of the immunoreactions, tumors and normal epithelium of bile ducts were considered negative if less than $5 \%$ of cells reacted. The staining pattern was designated focal if less than $25 \%$ of the cells showed positive reaction. The intensity of the reaction was evaluated only for the cells expressing claudin-4 and compared with that of normal colonic mucosa. Cells that displayed a more intense or equal membranous staining pattern to that of normal colonic mucosa were considered to be strongly positive. Cells exhibiting a considerably lower intensity than normal mucosa were described as being low-level positive.

For claudin-4 and laminin double-labeling immunofluorescence was carried out. Laminin immunostaining was used to substantiate the glandular structure of low-grade tumors and the solid growth pattern characteristic of high-grade tumors in immunofluorescence microscopy. Cryostat sections $(15 \mu \mathrm{m})$ were fixed in methanol $\left(-20^{\circ} \mathrm{C}\right.$ for $\left.10 \mathrm{~min}\right)$ and incubated overnight with a mixture of mouse anticlaudin-4 antibody and rabbit antilaminin antibody (diluted 1:100, rabbit polyclonal, cat\# Z0097; DAKO). After washing with PBS, fluorescein isothiocyanate-conjugated anti-mouse IgG (diluted
1:100, cat\# F5262; Sigma, St Louis, MO, USA) and tetramethylrhodamine $\mathrm{B}$ isothiocyanate-conjugated anti-rabbit IgG (diluted 1:20, cat\# R0156; DAKO) were used as secondary antibodies. Sections were examined by confocal laser-scanning microscope (Bio-Rad MRC-1024 system, Bio-Rad, Richmond, CA, USA) using the appropriated settings for the separate detection of emission signals from fluorescein isothiocyanate and rhodamine dyes.

\section{Western Blotting Analysis}

Proteins were extracted from eight snap frozen tissues of each tumor group together with normal livers. The isolation was carried out by using lysis buffer $(100 \mathrm{mM} \mathrm{NaCl}, 1 \%$ NP-40, $2 \mathrm{mM}$ EDTA, $50 \mathrm{mM}$ TRIS, $20 \mu \mathrm{g} / \mathrm{ml}$ aprotinin, $20 \mu \mathrm{g} / \mathrm{ml}$ leupeptin, $1 \mathrm{mM}$ PMSF, $\mathrm{pH}$ 7.5). Subsequently, the samples were mixed with $2 \times$ Laemmli sample buffer, boiled for $10 \mathrm{~min}$, followed by centrifugation at 13000 r.p.m. for $15 \mathrm{~min}$. Similar amounts of protein were loaded in each lane, run on $10 \%$ SDS-polyacrylamide gel electrophoresis, then transferred to nitrocellulose membranes. Blots were incubated with anticlaudin-4 (diluted 1:200) as primary antibody overnight. The biotinylated secondary antibody, goat anti-mouse IgG (diluted 1:2000, cat\# E0433; DAKO), was applied for $1 \mathrm{~h}$ at room temperature. Signals were visualized by chemiluminescent detection.

\section{Real-Time RT-PCR}

\section{RNA isolation}

Seven formalin-fixed, paraffin-embedded biliary tract cancers, 10 hepatocellular carcinomas and four normal liver specimens were selected for real-time RT-PCR analysis. Two to eight $5-\mu$ m-thick sections were cut from each tissue block (necrosis and bleeding excluded). Total RNA was isolated using High Pure RNA Paraffin Kit (Roche, Indianapolis, IN, USA) in accordance with the manufacturer's instructions.

\section{Reverse transcription of RNA}

An aliquot of total RNA (500 ng) was reverse transcribed for $10 \mathrm{~min}$ at $25^{\circ} \mathrm{C}, 50 \mathrm{~min}$ at $42^{\circ} \mathrm{C}$, and $5 \mathrm{~min}$ at $95^{\circ} \mathrm{C}$ in $30 \mu \mathrm{l}$ using MuLV reverse transcriptase (Applied Biosystems, Foster City, CA, USA) and random hexamers (Applied Biosystems).

\section{Real-time RT-PCR}

SYBR Green-based real-time RT-PCR reactions were performed in a $25 \mu \mathrm{l}$ mixture containing $2 \mu \mathrm{l}$ of cDNA sample and $300 \mathrm{nmol} / \mathrm{l}$ of each primer, using the ABI PRISM 7000 Sequence Detection System (Applied Byosystems). The following primer pairs were used: claudin-4 (GI:14790131), 5'-GGCTGCTT TGCTGCAACTGTC-3' (741-761), 5'-GAGCCGTGGC ACCTTACACG-3' (829-848); $\beta$-actin (GI:15928802), 
5'-CCTGGCACCCAGCACAAT-3' (1031-1048), 5'-GG GCCGGACTCGTCATAC-3' (1157-1174). After $10 \mathrm{~min}$ of initial denaturation at $95^{\circ} \mathrm{C}$, the cycling conditions of 40 cycles consisted of denaturation at $95^{\circ} \mathrm{C}$ for $20 \mathrm{~s}$, annealing at $60^{\circ} \mathrm{C}$ for $30 \mathrm{~s}$, and elongation at $72^{\circ} \mathrm{C}$ for $60 \mathrm{~s}$. PCR products were run on a $2 \%$ agarose gel to ensure that a right size product was amplified in the reaction. Relative expression software tool (REST) Pair Wise Fixed Reallocation Randomization Test was used to compare each sample group. The used mathematical model is based on the PCR efficiencies and the crossing point deviation between the samples. ${ }^{24}$ The expression level of claudin-4 was normalized by the housekeeping gene $\beta$-actin.

\section{Results}

\section{Claudin-4 Expression in Normal Liver, Biliary Tract Cancers and Hepatocellular Carcinomas}

The normal biliary epithelium expressed claudin-4 at a low level as detected by immunohistochemistry. Membranous staining was seen on the extrahepatic bile duct epithelium and larger intrahepatic bile ducts (Figure 2a). Even a less intensive membranous staining was detected in the interacinar portal bile ductules (Figure 2b). The hepatocytes of normal liver samples did not react with the claudin-4 antibody (Figures $1 \mathrm{~b}$ and $2 \mathrm{~b}$ ).

Of the 53 biliary tract cancer cases, 37 were well to moderately differentiated adenocarcinomas (Grade I-II) (Figure 2c), while 16 were poorly differentiated (Grade III). The hepatocellular carcinomas were categorized according to differentiation into well differentiated $(n=8)$ (Figure 2d), moderately differentiated $(n=19)$ or poorly differentiated $(n=23)$.

The immunohistochemical results are summarized in Table 1. All 53 biliary tract cancers reacted with anticlaudin-4, showing typical strong intense membrane-bound positivity in $100 \%$ of the tumor cells (Figures 1d, e and 2e). There was no difference in claudin-4 expression among the biliary tract cancers of different origin, namely intrahepatic-, extrahepatic- or gallbladder carcinomas. The grade of differentiation did not influence the claudin-4 immunoreaction, both well- and poorly differentiated tumor cells expressed intensive reaction with anticlaudin-4 (Figure 3a and b). The immunostaining was membranous, forming a 'honeycomb'-like appearance (Figure 2e). In contrast, none of the hepatocellular carcinomas showed positive immunostaining for claudin-4 (Figures 1c and 2f).

\section{CK, HSA Expression in Biliary Tract Cancers and Hepatocellular Carcinomas}

CK7 expression was observed in a total of $49 / 53$ biliary tract cancers (92\%); $22(96 \%)$ gallbladder tumors, $13(100 \%)$ common bile duct tumors, nine
(90\%) hepatic duct tumors and five (71\%) intrahepatic (peripheral) bile duct tumors. In all, 17 out of the $50(34 \%)$ hepatocellular carcinoma cases, however, showed focal positivity as well (Table 1). All normal bile ducts were uniformly CK7 positive.

CK19 expression was noted in most of the biliary tract cancers $(83 \%)$ studied, staining 20 (87\%) gallbladder carcinomas, $11(85 \%)$ common bile duct carcinomas, eight $(80 \%)$ hepatic duct tumors, and five $(71 \%)$ intrahepatic biliary tract cancers. CK19 reactivity was absent in all hepatocellular carcinomas (Table 1). Normal biliary epithelium showed intense positivity for this antibody in all localizations studied.

CK20 expression was present in 14/53 biliary tract cancers $(26 \%)$, staining seven $(30 \%)$ gallbladder cancers, four (31\%) common bile duct tumors, three $(30 \%)$ hepatic duct tumors and none of the intrahepatic biliary tract cancers. In contrast, expression of CK20 was observed in only two (4\%) of the hepatocellular carcinoma cases (Table 1). CK20 staining was absent in the normal extra- and intrahepatic biliary epithelium.

HSA was detected in 43 out of the 50 hepatocellular carcinomas $(86 \%)$, however, a total of $4 / 53$ biliary tract cancers (8\%) including two (9\%) gallbladder and two (15\%) common bile duct tumors showed focal positivity as well (Table 1).

Sensitivity and specificity of immunoreactions detected in biliary tract cancers were calculated as 100 and $100 \%$ for claudin-4, 92 and $66 \%$ for CK7, 83 and $100 \%$ for CK19, 26 and $96 \%$ for CK20 and 8 and $14 \%$ for HSA, respectively.

\section{Double Immunoflourescence Localization of Claudin-4 and Laminin}

For more precise localization, double immunofluorescence labeling was performed using anticlaudin-4 (in green) and antibody directed against the basement membrane protein laminin (in red), followed by confocal scanning. Claudin-4 gave strong labeling of the bile duct tumor cell membranes in all cases studied (Figure 4a). Well-differentiated biliary tract cancers had continuous laminin staining, whereas on less differentiated parts of the tumor the basement membrane was fragmented or absent (Figure $4 \mathrm{~b}$ ), characteristic of this type of tumor. Claudin-4 was absent in all hepatocellular carcinoma cases (not shown).

\section{Western Blot Analysis of Claudin-4 Expression}

Western blotting was used to analyze and confirm the increased claudin-4 protein expression detected in the biliary tract cancers by immunohistochemistry (Figure 5). A strong immunoreactive band of claudin-4 at $\mathrm{M}_{\mathrm{r}} 22000$ was observed only in bile duct tumors. Claudin-4 could not be demonstrated in hepatocellular carcinomas and normal liver tissues (Figure 5). 

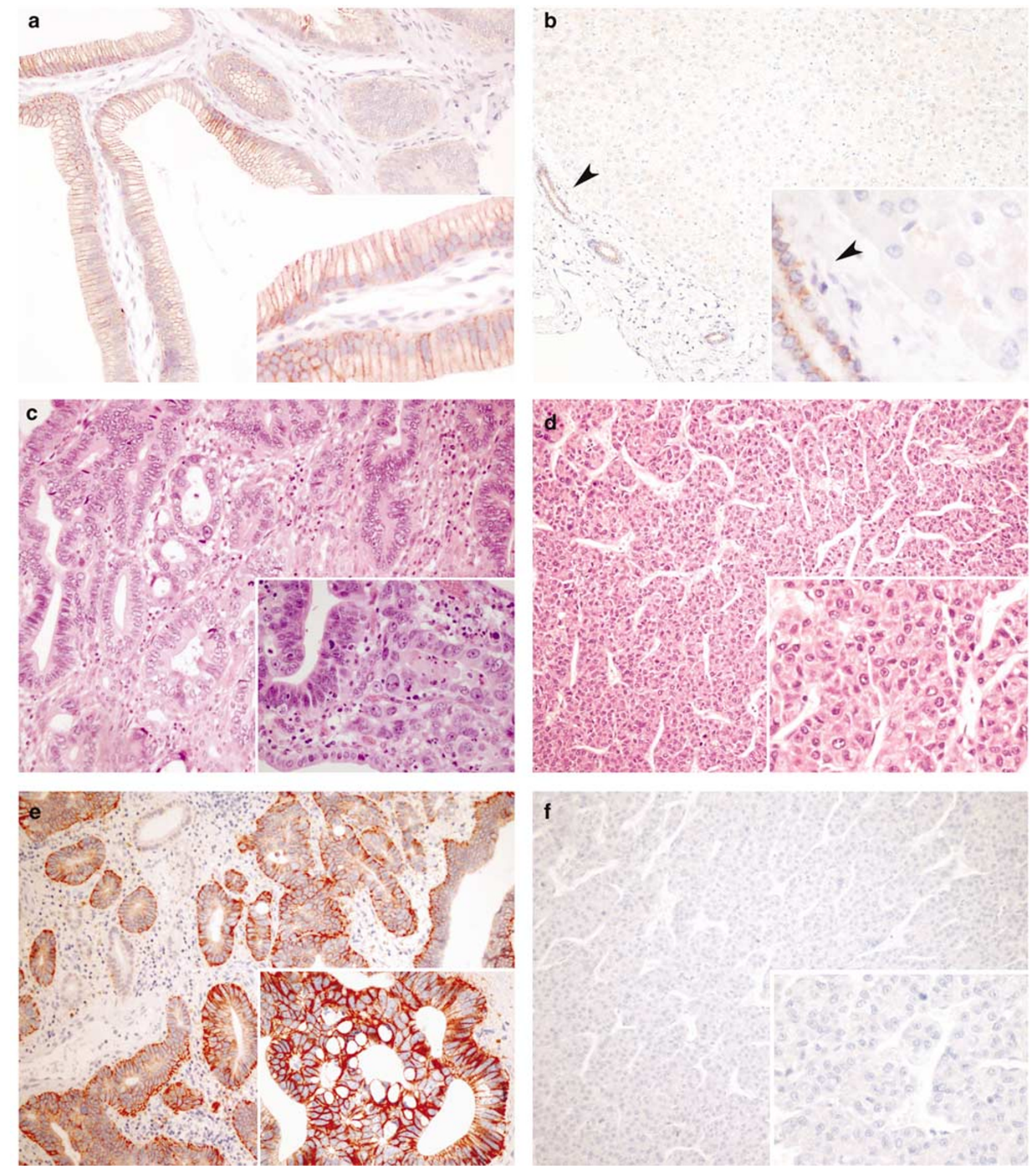

Figure 2 (a) Claudin-4 membranous immunostaining of the normal biliary epithelium in a large extrahepatic bile duct. (b) Claudin-4stained normal liver tissue. Low claudin-4 expression in the small bile ductule (arrowhead). (c) Moderately differentiated gallbladder carcinoma. (d) Well-differentiated hepatocellular carcinoma. (e) Intense membranous staining of claudin-4 in common bile duct cancer. (f) Hepatocellular carcinoma shows no claudin-4 expression. Magnification $\times 150$. Inset magnification $\times 400$.

\section{Claudin-4 mRNA Expression}

The relative expression level of mRNA evaluated by real-time RT-PCR revealed that the claudin-4 was significantly higher in biliary tract cancer specimens than in hepatocellular carcinoma specimens (48-fold increase, $P<0.001)$ using $\beta$-actin as reference gene (Figure 6). Claudin-4 was also upregulated (95-fold, $P<0.001$ ) in the biliary tract cancer sample group as compared with the normal liver sample group. No 

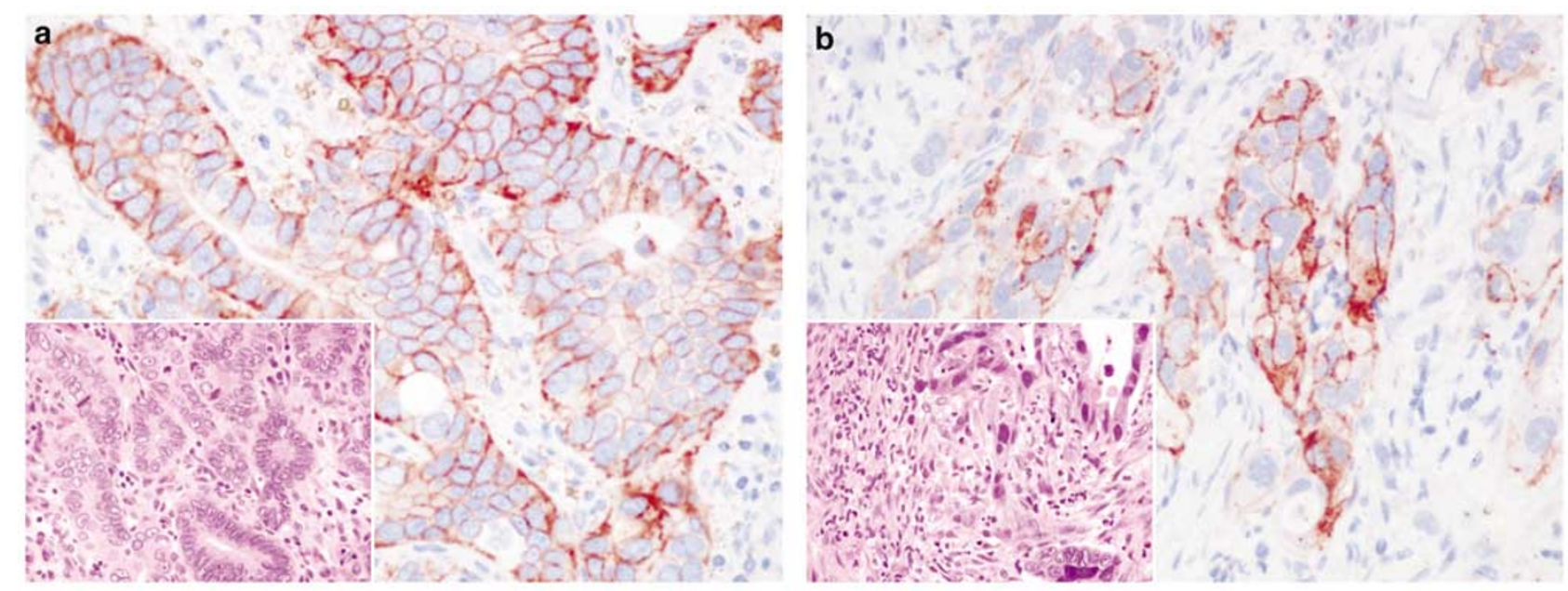

Figure 3 Strong membranous claudin-4 staining in well-differentiated (a) and poorly differentiated (b) biliary tract cancer.
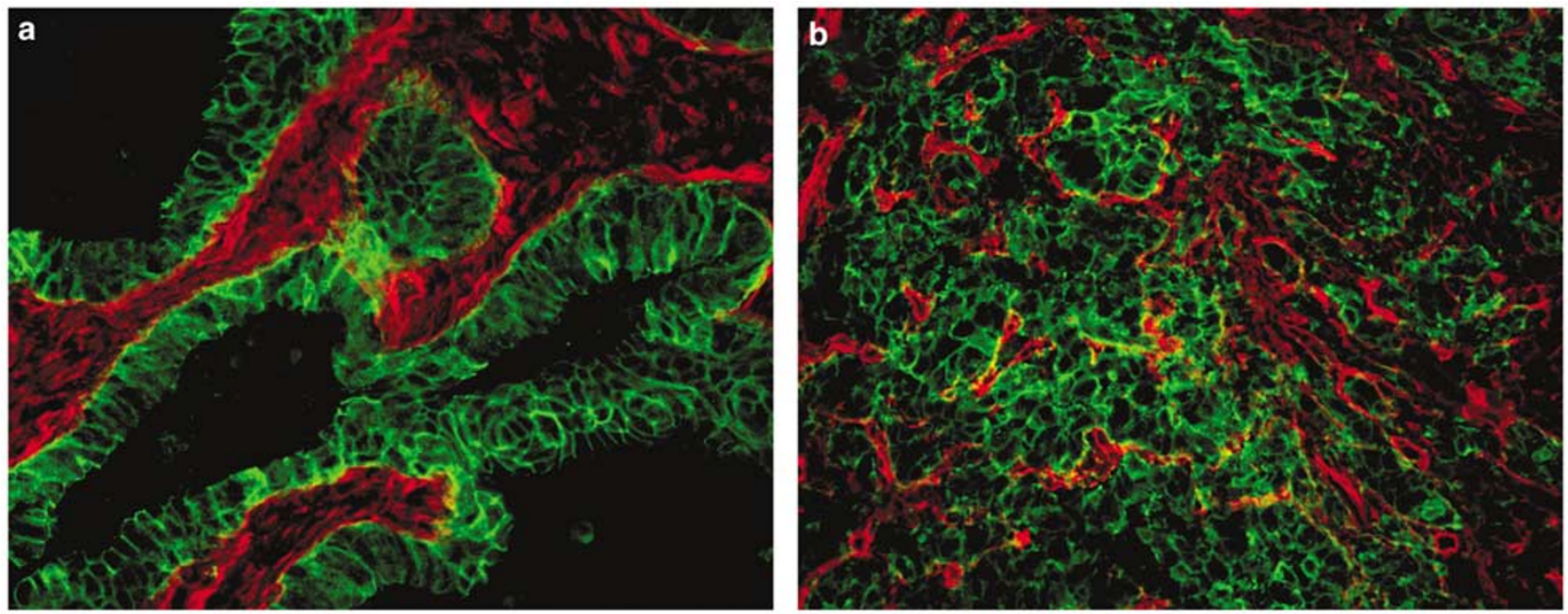

Figure 4 Dual immunofluorescence with anticlaudin-4 (green) and antilaminin (red) antibodies detected on frozen section by confocal laser scanning microscopy. (a) Glandular structure of low-grade biliary tract cancer. Strong membranous reaction for claudin-4 on tumor cells. Laminin shows proof of the glandular structure. (b) Solid growth pattern characteristic of high-grade tumors. Equally strong claudin-4 staining on tumor cells as seen in low-grade biliary tract cancer. Magnification (a) $\times 280,(\mathbf{b}) \times 400$.

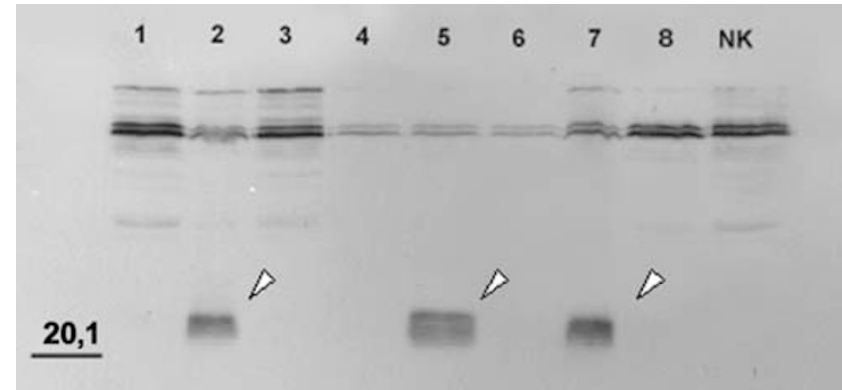

Figure 5 Representative result of Western immunoblot analysis. Appearance of claudin-4 positivity solely in case of the biliary tract cancers (arrowheads, lanes 2,5 and 7). The position of the molecular mass marker $(\mathrm{kDa})$ is indicated. The samples in lanes 1 and 4 are from hepatocellular carcinomas; lanes 3, 6 and 8 represent normal liver tissue. NK-negative control from normal liver.

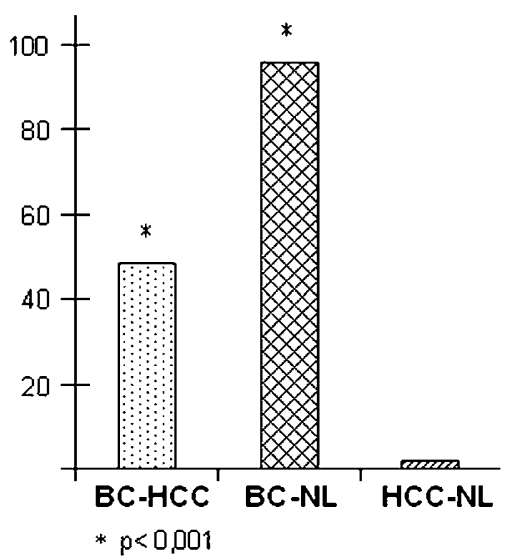

Figure 6 Fold change differences in claudin-4 mRNA expression by real-time RT-PCR reaction of biliary tract cancer (BC), hepatocellular carcinoma (HCC) and normal liver (NL). Claudin4 mRNA is significantly higher in BC as compared to HCC and NL. 
significant difference was found between hepatocellular carcinomas and normal liver samples.

\section{Discussion}

In this study, we clearly demonstrated a strong expression of claudin-4 in biliary cancers of different extrahepatic and intrahepatic origin. On the contrary, no expression of claudin-4 was detected in hepatocellular carcinomas. The normal extrahepatic and intrahepatic biliary epithelium usually expressed the claudin-4 protein with much less intensity than the tumors, the hepatocytes were negative. Claudin-4 mRNA levels strongly correlated with the results found for protein expression.

Claudin-4 is one of the transmembrane proteins of tight junctions expressed in several normal epithelial cells as gastrointestinal mucosa,${ }^{25}$ prostate,${ }^{20}$ cervical squamous epithelium, ${ }^{26}$ etc. The exact physiological function of claudin-4 is not clear. It creates a charge-selective pore in the paracellular pathway across the epithelia and selectively restricts passage of sodium in the paracellular space. ${ }^{27}$ Significant increase of claudin-4 has been detected in pancreatic ${ }^{22,28}$ prostate, ${ }^{20}$ cervical $^{26}$ and ovarian cancers. ${ }^{29}$

For the first time, our study detected high expression of claudin-4 in biliary tract cancers in contrast to hepatocellular carcinomas at both RNA and protein levels. This is in correlation with its expression in normal extrahepatic and intrahepatic bile ducts, gallbladder mucosa and its absence from hepatocytes shown by immunohistochemistry.

The absence of claudin-4 in mature hepatocytes and hepatocellular carcinomas and its increased expression in biliary epithelium and biliary tract cancers suggest that the expression pattern of the constituents and composition of tight junctions are quite stable and characteristic in epithelial cells of the liver and extrahepatic biliary system, not being influenced by tumorous proliferation, at least not in case of claudin-4. On the other hand, losing claudin4 expression might be considered a marker of hepatocytic differentiation, similarly to the loss of CK7 expression.

Metastatic adenocarcinomas of unknown origin occasionally present significant clinical dilemmas in regard to diagnosis and therapy. Our study reported increased claudin-4 expression in biliary tract cancers in contrast to hepatocellular carcinomas. Claudin-4, however, does not distinguish between biliary tract cancers and metastatic adenocarcinomas. Therefore, the presence of increased claudin-4 expression should be interpreted with caution.

There is evidence that the liver contains a dormant stem cell compartment that is activated following hepatocyte injury. ${ }^{30,31}$ The identity of these cells remains controversial. It is believed that the small terminal bile ductules that form the canals of Hering constitute the primary hepatic stem cell niche. ${ }^{32}$ The progeny of the stem cells are the oval cells, which can differentiate along hepatocytic, biliary, intestinal, and pancreatic lineages in various rodent model systems. ${ }^{33,34}$ These findings suggest that hepatocytes might be reproduced from both bile duct cells and hepatic stem cells. ${ }^{35,36}$ Therefore, it is quite unexpected for the hepatocytes and the tumors deriving from them not to express claudin-4.

The 'relative stability' of claudin-4 in biliary epithelium, however, might not be valid for other tissues and organs or other members of the claudin family. The expression of several other types of claudins has been shown to change during tumor formation, as claudin-1 in carcinomas of the breast ${ }^{37}$ and colon, ${ }^{38,39}$ claudin-3 in breast, ${ }^{19}$ prostate ${ }^{20}$ and ovarian $^{40}$ cancers, and claudin-7 in breast carcinomas. ${ }^{41}$ Furthermore, increased expression of mRNAs encoding claudin-1, $-3,-4$ and -7 has been detected in a great variety of human carcinoma cell lines of different origins. ${ }^{42}$

In the majority of tumors studied, continuous decrease of claudin expression has been detected during disease progression, especially in breast, ${ }^{41}$ cervical ${ }^{26}$ and colon carcinomas. ${ }^{39}$ Interestingly, this is not the case for claudin-4, where increased expression could be observed in invasive cancers of the pancreas and ovaries as compared with normal tissue. Based on our study, a similar situation seems to be present in case of tumors of biliary origin.

The intermediate filaments, CKs, are characteristic for epithelial cells. To date, at least 20 distinct polypeptides which belong to this family have been identified in various human epithelial cell types and their tumors. ${ }^{43}$ CK7, 19 and 20 are helpful diagnostic markers of bile ducts and the tumors derived from them. Our results show that the majority of biliary tract cancers express CK7 and CK19, which corresponds to previous studies. ${ }^{44,45}$ However, some hepatocellular carcinomas also express CK7. CK20 was detected both in biliary tract cancers and hepatocellular carcinomas, however, in low percentage of the cases. These data suggest that the claudin expression pattern, at least that of claudin-4, differentiates the biliary tumors and tumors of hepatocellular origin even better than-or at least equally as well as-the CK pattern. This phenomenon might provide additional information regarding histogenesis.

One of the most widely applied antibodies used in the differential diagnosis of hepatocellular tumors is HSA (HepPar1). The target antigen is not exactly known, the staining pattern suggests a possible mitochondrial localization. ${ }^{10}$ Claudin-4 gives a 'mirror image' of HSA, being negative in hepatocellular carcinomas and strongly positive in tumors of biliary origin, which might be added to a panel approach regarding differentiation of hepatic and biliary tumors.

Claudin-4 functions as the receptor for $C$. perfringens enterotoxin. ${ }^{18}$ Binding of $C$. perfringens enterotoxin to tumor cells expressing claudin-4 led to an 
acute dose-dependent cytotoxic response correlating with claudin-4 expression. ${ }^{19,21}$ Successful elimination of claudin-4-positive tumor cells might open new perspectives for a novel therapeutic approach. For this reason, detection of high claudin-4 expression in tumors is also likely to have therapeutic importance besides application in differential diagnosis.

\section{Acknowledgements}

We thank Ágnes Szik, Magdolna Pekár and Júlia Oláh for their excellent assistance. This work was supported by Grants NKFP-1/0023/2002 from the Hungarian Ministry of Education, National Research Development Projects and ETT-077/2003 from the Hungarian Ministry of Health.

\section{References}

1 El-Serag HB, Davila JA, Petersen NJ, et al. The continuing increase in the incidence of hepatocellular carcinoma in the United States: an update. Ann Intern Med 2003;139:817-823.

2 Davila JA, El-Serag HB. Cholangiocarcinoma: the 'other' liver cancer on the rise. Am J Gastroenterol 2002;97:3199-3200.

3 Maeda T, Adachi E, Kajiyama K, et al. Combined hepatocellular and cholangiocarcinoma: proposed criteria according to cytokeratin expression and analysis of clinicopathologic features. Hum Pathol 1995;26: 956-964.

4 Itamoto T, Asahara T, Katayama K, et al. Double cancer-hepatocellular carcinoma and intrahepatic cholangiocarcinoma with a spindle-cell variant. J Hepatobiliary Pancreat Surg 1999;6:422-426.

5 Harada K, Masuda S, Hirano M, et al. Reduced expression of syndecan-1 correlates with histologic dedifferentiation, lymph node metastasis, and poor prognosis in intrahepatic cholangiocarcinoma. Hum Pathol 2003;34:857-863.

6 Shibahara H, Tamada S, Higashi M, et al. MUC4 is a novel prognostic factor of intrahepatic cholangiocarcinoma-mass forming type. Hepatology 2004;39: 220-229.

7 Sugimachi K, Taguchi K, Aishima S, et al. Altered expression of beta-catenin without genetic mutation in intrahepatic cholangiocarcinoma. Mod Pathol 2001;14: 900-905.

8 Cabibi D, Licata A, Barresi E, et al. Expression of cytokeratin 7 and 20 in pathological conditions of the bile tract. Pathol Res Pract 2003;199:65-70.

9 Aishima S, Asayama Y, Taguchi K, et al. The utility of keratin 903 as a new prognostic marker in massforming-type intrahepatic cholangiocarcinoma. Mod Pathol 2002;15:1181-1190.

10 Minervini MI, Demetris AJ, Lee RG, et al. Utilization of hepatocyte-specific antibody in the immunocytochemical evaluation of liver tumors. Mod Pathol 1997;10:686-692.

11 Tsukita S, Furuse M, Itoh M. Multifunctional strands in tight junctions. Nat Rev Mol Cell Biol 2001;2: 285-293.
12 Johnson LG. Applications of imaging techniques to studies of epithelial tight junctions. Adv Drug Deliv Rev 2005;57:111-121.

13 Hadj-Rabia S, Baala L, Vabres P, et al. Claudin-1 gene mutations in neonatal sclerosing cholangitis associated with ichthyosis: a tight junction disease. Gastroenterology 2004;127:1386-1390.

14 Heiskala M, Peterson PA, Yang Y. The roles of claudin superfamily proteins in paracellular transport. Traffic 2001;2:93-98.

15 Morita K, Furuse M, Fujimoto K, et al. Claudin multigene family encoding four-transmembrane domain protein components of tight junction strands. Proc Natl Acad Sci USA 1999;96:511-516.

16 Turksen K, Troy TC. Barriers built on claudins. J Cell Sci 2004;117:2435-2447.

17 Soini Y. Expression of claudins 1, 2, 3, 4, 5 and 7 in various types of tumours. Histopathology 2005; 46:551.

18 Katahira J, Inoue N, Horiguchi Y, et al. Molecular cloning and functional characterization of the receptor for Clostridium perfringens enterotoxin. J Cell Biol 1997;136:1239-1247.

19 Kominsky SL, Vali M, Korz D, et al. Clostridium perfringens enterotoxin elicits rapid and specific cytolysis of breast carcinoma cells mediated through tight junction proteins claudin 3 and 4 . Am J Pathol 2004;164:1627.

20 Long H, Crean CD, Lee WH, et al. Expression of Clostridium perfringens enterotoxin receptors claudin3 and claudin- 4 in prostate cancer epithelium. Cancer Res 2001;61:7878-7881.

21 Michl P, Buchholz M, Rolke M, et al. Claudin-4: a new target for pancreatic cancer treatment using Clostridium perfringens enterotoxin. Gastroenterology 2001; 121:678-684.

22 Nichols LS, Ashfaq R, Iacobuzio-Donahue CA. Claudin 4 protein expression in primary and metastatic pancreatic cancer: support for use as a therapeutic target. Am J Clin Pathol 2004;121:226-230.

23 McClane BA, McDonel JL. The effects of Clostridium perfringens enterotoxin on morphology, viability, and macromolecular synthesis in Vero cells. J Cell Physiol 1979;99:191-200.

24 Pfaffl MW, Horgan GW, Dempfle L. Relative expression software tool (REST) for group-wise comparison and statistical analysis of relative expression results in real-time PCR. Nucl Acid Res 2002;30:e36.

25 Gonzalez-Mariscal L, Betanzos A, Nava P, et al. Tight junction proteins. Prog Biophys Mol Biol 2003;81: $1-44$.

26 Sobel G, Páska C, Szabó I, et al. Increased expression of claudins in cervical squamous intraepithelial neoplasia and invasive carcinoma. Hum Pathol 2005;36: 162-169.

27 Van Itallie C, Rahner C, Anderson JM. Regulated expression of claudin-4 decreases paracellular conductance through a selective decrease in sodium permeability. J Clin Invest 2001;107:1319-1327.

28 Tsukahara M, Nagai H, Kamiakito T, et al. Distinct expression patterns of claudin-1 and claudin-4 in intraductal papillarymucinous tumors of the pancreas. Pathol Int 2005;55:63.

29 Hibbs K, Skubitz KM, Pambuccian SE, et al. Differential gene expression in ovarian carcinoma: identification of potential biomarkers. Am J Pathol 2004;165:397-414. 
30 Fausto N, Campbell JS. The role of hepatocytes and oval cells in liver regeneration and repopulation. Mech Develop 2003;120:117-130.

31 Roskams T, Yang SQ, Koteish A, et al. Oxidative stress and oval cell accumulation in mice and humans with alcoholic and nonalcoholic fatty liver disease. Am J Pathol 2003;163:1301-1311.

32 Paku S, Schnur J, Nagy P, et al. Origin and structural evolution of the early proliferating oval cells in rat liver. Am J Pathol 2001;158:1313-1323.

33 Sell S. Is there a liver stem cell? Cancer Res 1990;50:3811-3815.

34 Shiojiri N, Lemire JM, Fausto N. Cell lineages and oval cell progenitors in rat liver development. Cancer Res 1991;51:2611-2620.

35 Evarts RP, Nagy P, Marsden E, et al. A precursorproduct relationship exists between oval cells and hepatocytes in rat liver. Carcinogenesis 1987;8: 1737-1740.

36 Lenzi R, Liu MH, Tarsetti F, et al. Histogenesis of bile duct-like cells proliferating during ethionine hepatocarcinogenesis. Evidence for a biliary epithelial nature of oval cells. Lab Invest 1992;66: 390-402.

37 Kramer F, White K, Kubbies M, et al. Genomic organization of claudin-1 and its assessment in hereditary and sporadic breast cancer. Hum Genet 2000;107:249-256.

38 Miwa N, Furuse M, Tsukita S, et al. Involvement of claudin-1 in the beta-catenin/Tcf signaling pathway and its frequent upregulation in human colorectal cancers. Oncol Res 2000;12:469-476.
39 Resnick MB, Konkin T, Routhier J, et al. Claudin-1 is a strong prognostic indicator in stage II colonic cancer: a tissue microarray study. Mod Pathol 2005;18: 511-518.

40 Heinzelmann-Schwarz VA, Gardiner-Garden M, Henshall SM, et al. Overexpression of the cell adhesion molecules DDR1, Claudin 3, and Ep-CAM in metaplastic ovarian epithelium and ovarian cancer. Clin Cancer Res 2004;10:4427-4436.

41 Kominsky SL, Argani P, Korz D, et al. Loss of the tight junction protein claudin-7 correlates with histological grade in both ductal carcinoma in situ and invasive ductal carcinoma of the breast. Oncogene 2003;22: 2021-2033.

42 Offner S, Hekele A, Teichmann U, et al. Epithelial tight junction proteins as potential antibody targets for pancarcinoma therapy. Cancer Immunol Immunother 2005;54:431-445.

43 Moll R, Franke WW, Schiller DL, et al. The catalog of human cytokeratins: patterns of expression in normal epithelia, tumors and cultured cells. Cell 1982;31: 11-24.

44 Porcell AI, De Young BR, Proca DM, et al. Immunohistochemical analysis of hepatocellular and adenocarcinoma in the liver: MOC31 compares favorably with other putative markers. Mod Pathol 2000;13: 773-778.

45 Lau SK, Prakash S, Geller SA, et al. Comparative immunohistochemical profile of hepatocellular carcinoma, cholangiocarcinoma, and metastatic adenocarcinoma. Hum Pathol 2002;33:1175-1181. 